\title{
A CLINICAL STUDY OF TREATMENT OF PROXIMAL TIBIA FRACTURE WITH LOCKING COMPRESSION PLATE
}

\author{
Prashanth Chalasani ${ }^{1}$, K. Satya Kumar ${ }^{2}$, Kavya Mikkineni ${ }^{3}$ \\ ${ }^{1}$ Senior Resident, Department of Orthopaedics, NRI Academy of Sciences. \\ 2 Professor, Department of Orthopaedics, NRI Academy of Sciences. \\ 3Junior Resident, Department of Orthopaedics, NRI Academy of Sciences.
}

\begin{abstract}
BACKGROUND

Incidence of fracture of the proximal tibia are increasing regularly due to RTA. Being one of the major weight bearing joint of the body fracture around it will be of paramount importance. The recent development of LCP has revolutionised the treatment by overcoming the few drawbacks of conventional buttress plate. The LCP is an internal fixation system, which is a hybrid of LC-DCP and LISS. The LCP can be applied in three different ways: (a) As compression plate, (b) As combining compression and bridge plating, and (c) As pure internal fixation (bridge plating).
\end{abstract}

\section{MATERIALS AND METHODS}

We studied 21 patients involving proximal tibia fracture, among them 5 patients with MIPPO technique and 16 patients with ORIF technique.

\section{RESULTS}

We followed up all the patients until union of fractures ranged from 16 - 24 weeks. The average time for union of fracture was 18 weeks, ranged from 16 - 24 weeks. Those plate bridge with the MIPPO technique healed even earlier. We had total 6 complications including 2 knee joint stiffness, 1 post-operative loss of reduction, 1 infection, 1 varus deformity and 1 case of knee instability. We had no case of any purely implant related complication like screw loosening, screw breakage or plate failure.

\section{CONCLUSION}

The patient's sample approximately reflected the regular trauma patients encountered at our setup, fracture treated with bridge plating and combined principle of conventional and internal fixation (bridge plating) healed rapidly by secondary fracture union and hence achieving strong union across the fracture at a much earlier time compared to LCP as conventional plate. The MIPO type of reduction and fixation was less time consuming, less soft tissue injury, so preserve the bone blood supply subsequently helps in healing of both soft tissue and bone faster.

\section{KEYWORDS}

Locking Compression Plate; Internal Fixator; Bridge Plating; MIPPO.

HOW TO CITE THIS ARTICLE: Chalasani P, Kumar KS, Mikkineni K. A clinical study of treatment of proximal tibia fracture with locking compression plate. J. Evolution Med. Dent. Sci. 2016;5(88):6546-6552, DOI: 10.14260/jemds/2016/1481

\section{BACKGROUND}

The majority of tibial plateau fractures are secondary to high speed velocity accidents and fall from height, where fractures result from direct axial compression, usually with a valgus (more common) or varus moment and indirect shear forces. ${ }^{1}$

Extra-articular fractures of the proximal tibia usually secondary to direct bending forces applied to the metadiaphyseal region of the upper leg, older patients with osteopenic bone are more likely to sustain depression type fracture, because their subchondral bone is less likely to resist axial-directed loads. ${ }^{2}$

Financial or Other, Competing Interest: None.

Submission 29-12-2015, Peer Review 24-01-2016,

Acceptance 30-01-2016, Published 02-11-2016.

Corresponding Author:

Dr. K. Satya Kumar,

Flat 101,

Kanchukota, $N$ K Habitate,

Gayatri Nagar,

Vijayawada-520008,

Andhra Pradesh.

E-mail: kodurusk@gmail.com

DOI: $10.14260 /$ jemds $/ 2016 / 1481$
The aim of surgical treatment of proximal tibia fracture is to restore congruent articular surfaces of the tibial condyles maintaining the mechanical axis and restoring ligamentous stability eventually can achieve functional painless and good range of motion in the knee joint. 3

The various clinical studies established that bone beneath a rigid conventional plate are thin and atrophic, which are prone for secondary displacement due to insufficient buttressing and secondary fractures after removal of plate, fracture site take longer period to osteosynthesis due to interruption of vascular supply to bone due to soft tissue and periosteal stripping.

So there was the birth of a new concept of biological fixation using the plates, otherwise called minimally invasive plate osteosynthesis (MIPPO). But this was difficult as conventional plates needed to be accurately contoured to achieve good fixation, osteoporosis also posed the same problem of poor fixation with conventional plates. 4

This leads to the development of the internal fixators. PCfix I and later PC fix II. As more and more concepts about biological fixation become clearer, the innovation of plates progressed lead to development of Less Invasive Stabilising System (LISS). 
Research to combine these two methods has led to the development of the AO Locking Compression Plate (LCP). 5

This new system has been regarded as technically mature. It offers numerous fixation possibilities and has proven worth in complex fracture situations and in osteoporosis. 2

\section{The Concepts of Biological Fixation Consists of ${ }^{6}$}

- Indirect reduction.

- Adequate stability.

- Preservation of osteogenic potential.

- Limited bone - plate contact.

\section{MATERIALS AND METHODS}

The study was carried out in N.R.I. Medical College and General Hospital, Chinnakakani, Guntur from September 2013 to October 2015. The total number of cases studied were 21 with the youngest $18 \mathrm{yrs}$. and oldest $65 \mathrm{yrs}$.

The intention of this dissertation was to study the treatment of proximal tibial fracture with locking compression plate to obtain a stable, pain free mobile joint to prevent the development of osteoarthritis.

\section{Inclusion Criteria}

- Adult (Aged over 18 yrs.), both male and female.

\section{Exclusion Criteria}

- Patient aged below 18 yrs.

- Type II and III compound fractures.

On admission, demographic data was recorded and thorough history and clinical examination was done. We assessed the soft tissue injuries even in the closed fractures followed by radiological assessment of the fracture with Schatzker's classification.

As soon as the Operation was Planned, Certain Routine Procedures Like

1. Use of preoperative antibiotics and continued till the removal of suture.

2. Stabilise the patient haemodynamically and physical fitness for surgery was obtained.

3. Preoperative planning for selection of plate. Approach MIPPO technique or open reduction and internal fixation.

4. In our series, all fractures are reduced with traction in fracture table with $\mathrm{C}$-arm guidance.

5. To check for any associated fracture.

We treated 5 patients with minimally invasive plate osteosynthesis and 16 patients with open reduction and internal fixation.

The approach was either anteromedial parapatellar or anterolateral parapatellar incision.

The primary difference with the locking compression plate is the method of locking head screw insertion. Here, since the locking head of the screw has to get locked in the locking part of the combi-hole. The direction of the drilling has to be perfect. Hence, drilling for all locking head screws has to be after fixing the screw in drill sleeve.

We also made sure that whenever using the non-locking regular screw in the fixation. They were inserted prior to the insertion of the locking screws.

\section{Post-Operative}

In the immediate postoperative period, care was given to the general condition, fluid balance, IV antibiotics and analgesics as per the protocol. This helped us to mobilise the patient faster.

\section{Mobilisation}

Whenever stable internal fixation was achieved. The patient was mobilised after $48 \mathrm{hrs}$., after removal of the drains. For 2 3 days the range of motion allowed was $0-200$, from the $5^{\text {th }}$ day the range of motion was gradually allowed to be increased to 900 more, after suture removal full range of movement was allowed.

Whenever there was doubt about the stable fixation, external splinting in the form of Plaster of Paris slab was given for support and advised to do static quadriceps exercises. Continuous Passive Motion Exercise (CPM) were done daily with temporary removal of slab under careful supervision and splint reapplied. Partial weight bearing was delayed until 6 weeks and full weight bearing allowed after 12 - 16 weeks.

\section{Followup}

The first followup was usually between 6 - 8 weeks and later on patients were followed up at regular interval of 6 - 8 weeks till complete fracture union.

\section{During Followup}

1. The course of fracture healing was documented radiologically with minimum 6 weeks interval. The moment of complete healing was defined as radiologically complete bone regeneration at fracture site.

2. Evaluation of any possible loss of reduction.

3. Assessment and analysis of any complication. Followup of outpatients ranged from 16 weeks to 64 weeks.

\section{RESULTS AND OBSERVATIONS}

We studied 21 patients with 21 proximal tibial fractures, who were treated with locking compression plate (Buttress type).

\begin{tabular}{|c|c|c|}
\hline $\begin{array}{c}\text { Age Group } \\
\text { (Year) }\end{array}$ & $\begin{array}{c}\text { Number of } \\
\text { Patients }\end{array}$ & Percentage \\
\hline $18-20$ & 3 & 14.3 \\
\hline $21-30$ & 3 & 14.3 \\
\hline $31-40$ & 6 & 28.6 \\
\hline $41-50$ & 5 & 23.8 \\
\hline $51-60$ & 3 & 14.3 \\
\hline$>60$ & 1 & 4.7 \\
\hline Total & 21 & 100.0 \\
\hline \multicolumn{3}{|c|}{ Table 1: Age Distribution } \\
\hline
\end{tabular}

Most of the patients belonged to 31 - 50 yrs. of age group, who are more prone for RTA.

\begin{tabular}{|c|c|c|}
\hline Sex & $\begin{array}{c}\text { Number of } \\
\text { Patients }\end{array}$ & Percentage \\
\hline Male & 17 & 80.95 \\
\hline Female & 4 & 19.05 \\
\hline Total & $\mathbf{2 1}$ & $\mathbf{1 0 0 . 0}$ \\
\hline \multicolumn{3}{|c|}{ Table 2: Sex Distribution } \\
\hline
\end{tabular}

Most of our patients were male. It reflect the general population, which visit our both outpatient as well as the emergency trauma section. 


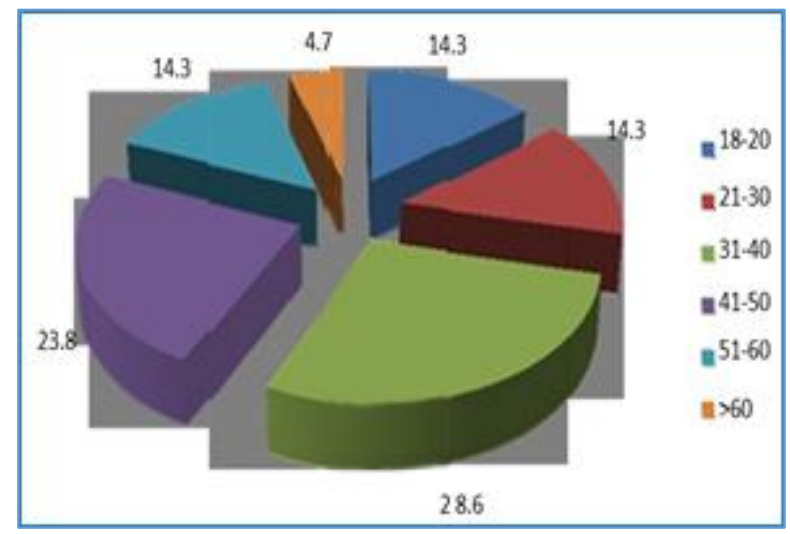

Graph 1: Age Distribution

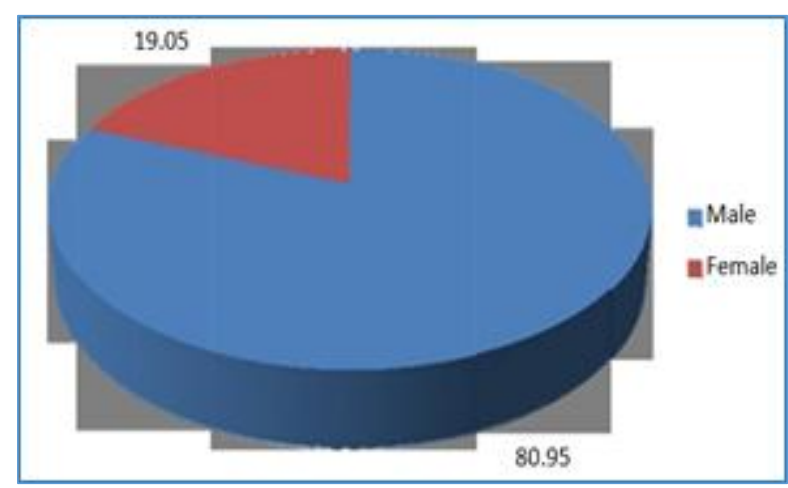

Graph 2: Sex Distribution

\begin{tabular}{|c|c|c|}
\hline Occupation & $\begin{array}{c}\text { Number of } \\
\text { Patients }\end{array}$ & Percentage \\
\hline Agriculturist & 5 & 23.80 \\
\hline Businessman & 4 & 19.07 \\
\hline Housewife & 3 & 14.28 \\
\hline Labourer & 6 & 28.57 \\
\hline Students & 3 & 14.28 \\
\hline Total & $\mathbf{2 1}$ & $\mathbf{1 0 0 . 0}$ \\
\hline \multicolumn{2}{|r|}{ Table 3: The Relationship of Fracture } \\
to Different Occupation \\
\hline
\end{tabular}

The tabular column clearly shows that the major preponderance of proximal tibia fracture is seen in people with a high level of activity, who indulge themselves in traveling because majority of the morbidity is due to RTA. Few of them sustain fracture through fall from height when they are climbing up ladder or stool to pick up object from the shelves.

\begin{tabular}{|c|c|c|}
\hline Laterality of Fracture & $\begin{array}{c}\text { Number of } \\
\text { Patients }\end{array}$ & Percentage \\
\hline Right & 12 & 57.14 \\
\hline Left & 09 & 42.86 \\
\hline Total & $\mathbf{2 1}$ & $\mathbf{1 0 0 . 0}$ \\
\hline \multicolumn{2}{|c|}{ Table 4: Laterality of Fracture } \\
\hline
\end{tabular}

In our series, there is a slight right-sided predominance compared to the left side.

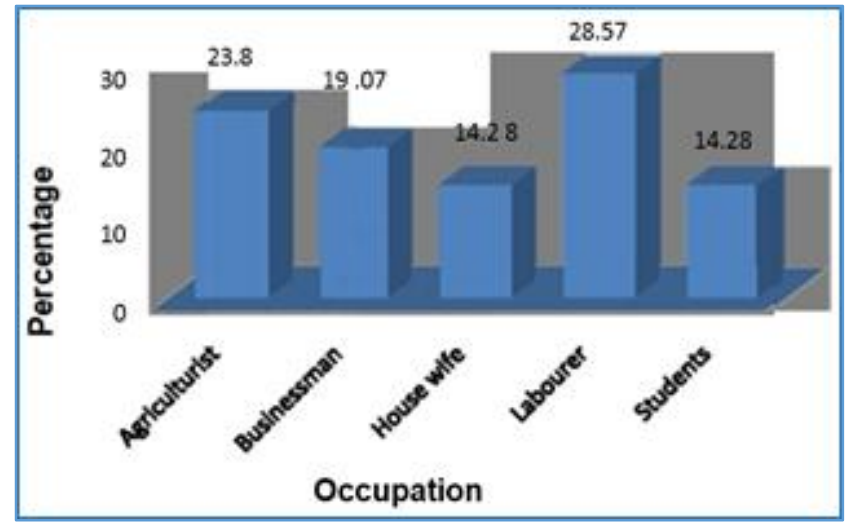

Graph 3: The Relationship of Fracture to Different Occupation



Graph 4: Laterality of Fracture

\begin{tabular}{|c|c|c|}
\hline Type of Fracture & $\begin{array}{c}\text { Number } \\
\text { of } \\
\text { Patients }\end{array}$ & Percentage \\
\hline I. Pure cleavage & 3 & 14.29 \\
\hline II. Cleavage with depression & - & - \\
\hline III. Central depression & - & - \\
\hline IV. Medial condyle fracture & 5 & 23.80 \\
\hline V. Bicondylar fracture & 6 & 28.57 \\
\hline $\begin{array}{l}\text { VI. Metaphyseal-diaphyseal } \\
\text { dissociation }\end{array}$ & 7 & 33.34 \\
\hline Total & 21 & 100.0 \\
\hline
\end{tabular}

In our series the majority of the fractures were found to be of type IV, V and VI fracture types, which are usually associated with high velocity road traffic accident.

\begin{tabular}{|c|c|c|}
\hline Method of Reduction & $\begin{array}{l}\text { Number of } \\
\text { Patients }\end{array}$ & Percentage \\
\hline ORIF & 16 & 76.19 \\
\hline MIPPO & 5 & 23.81 \\
\hline Total & 21 & 100.0 \\
\hline
\end{tabular}

We used MIPPO technique in 5 patients, both duration of procedure and soft tissue injuries are less compared to ORIF technique. Wound healing is also better and faster when compared to ORIF technique. It demands more surgical techniques and we found as the study progressed that the operative time need for MIPPO decreased as we matured more in this technique. 


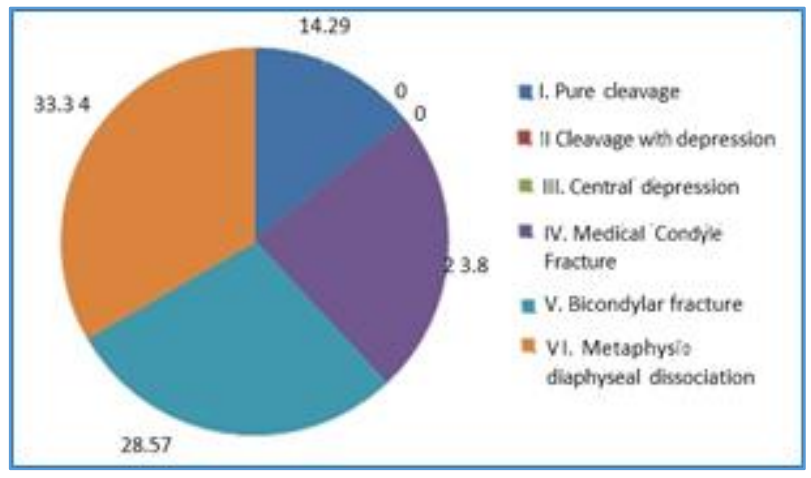

Graph 5: Type of Fracture and Percentage of Cases: Schatzker's Classification

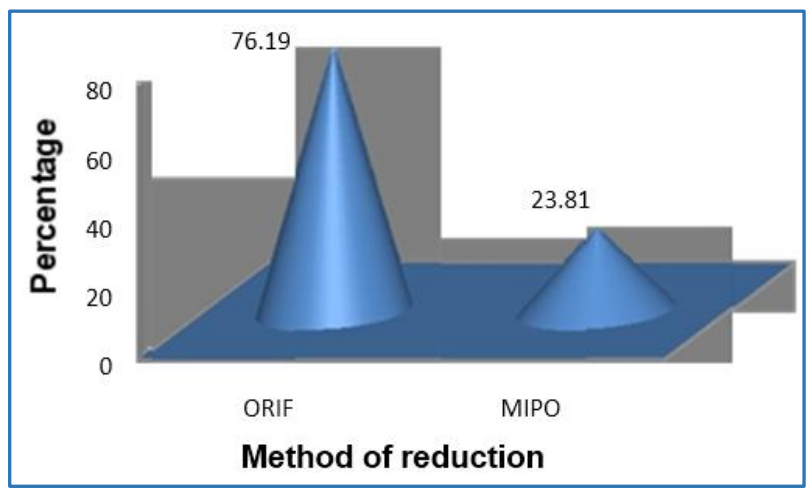

Graph 6: Method of Reduction and Fixation

\begin{tabular}{|c|c|c|}
\hline Principle & $\begin{array}{c}\text { Number of } \\
\text { Patients }\end{array}$ & Percentage \\
\hline Compression & 4 & 19.04 \\
\hline Bridging & 7 & 33.33 \\
\hline Combined & 10 & 47.63 \\
\hline Total & $\mathbf{2 1}$ & $\mathbf{1 0 0 . 0}$ \\
\hline \multicolumn{2}{|c|}{ Table 7: Principle of Fixation } \\
\hline
\end{tabular}

We used compression type for 4 patients, where both rigid fixation and buttress effect were needed. We used bridging type for 7 patients with fracture extending into metaphyseal region and lack of purchase to the screw due to comminution in metaphyseal region. Combined type was used in 10 patients, where articular reconstruction was essential and needed protection from collapsing in postoperative period.

\begin{tabular}{|c|c|c|}
\hline Side & $\begin{array}{c}\text { Number } \\
\text { of } \\
\text { Patients }\end{array}$ & Percentage \\
\hline Anteromedial & 10 & 47.62 \\
\hline Anterolateral & 11 & 52.38 \\
\hline Total & $\mathbf{2 1}$ & $\mathbf{1 0 0 . 0}$ \\
\hline \multicolumn{2}{|c|}{ Table 8: Surgical Approach } \\
\hline
\end{tabular}

We preferred anteromedial approach for 11 patients for fractures with medial condylar displacements and MIPPO technique of reduction and fixation is essential. This approach need less soft tissue stripping from bone and can contour plate appropriately. Anterolateral approach was done for 10 patients with lateral condylar displacement fractures and soft tissue injuries on medial side of proximal tibia.



Graph 7: Principle of Fixation

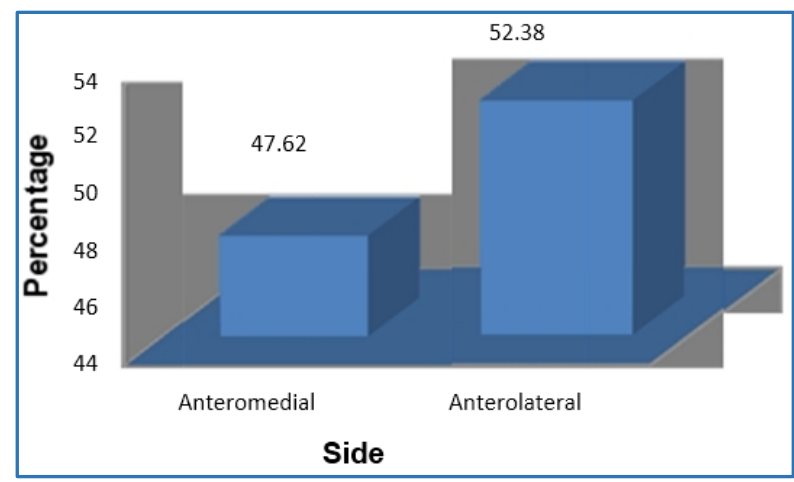

Graph 8: Surgical Approach

\begin{tabular}{|c|c|}
\hline Complication & $\begin{array}{c}\text { Number of } \\
\text { Patients }\end{array}$ \\
\hline Knee joint stiffness & 1 \\
\hline Postoperative loss of reduction & 1 \\
\hline Infection & 2 \\
\hline Varus deformity & 1 \\
\hline Knee instability & 1 \\
\hline \multicolumn{2}{|c|}{ Total } \\
Table 9: Complication \\
\hline
\end{tabular}

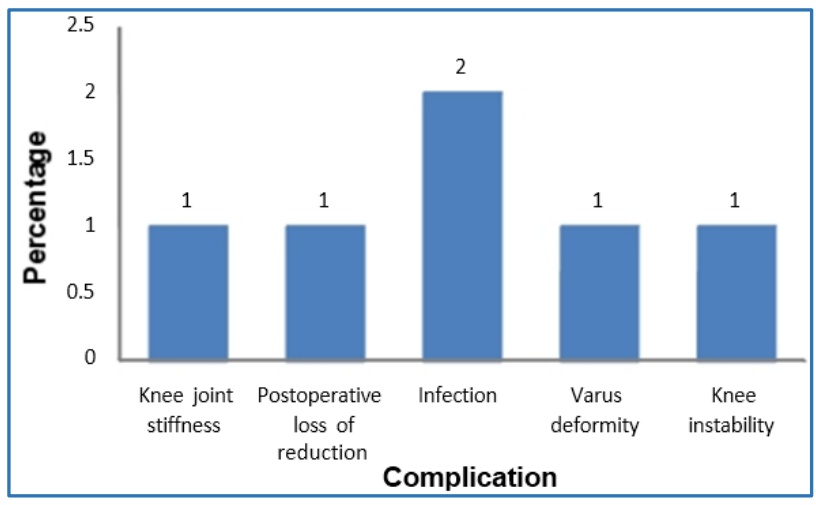

Graph 9: Complication

- We had no cases of any purely implant related complication like screw loosening, screw breakage and plate failure.

- $\quad$ Average time for union of fracture was 18 weeks (Range from 16 - 24 weeks).

Case

Pre-Operative X-Rays 

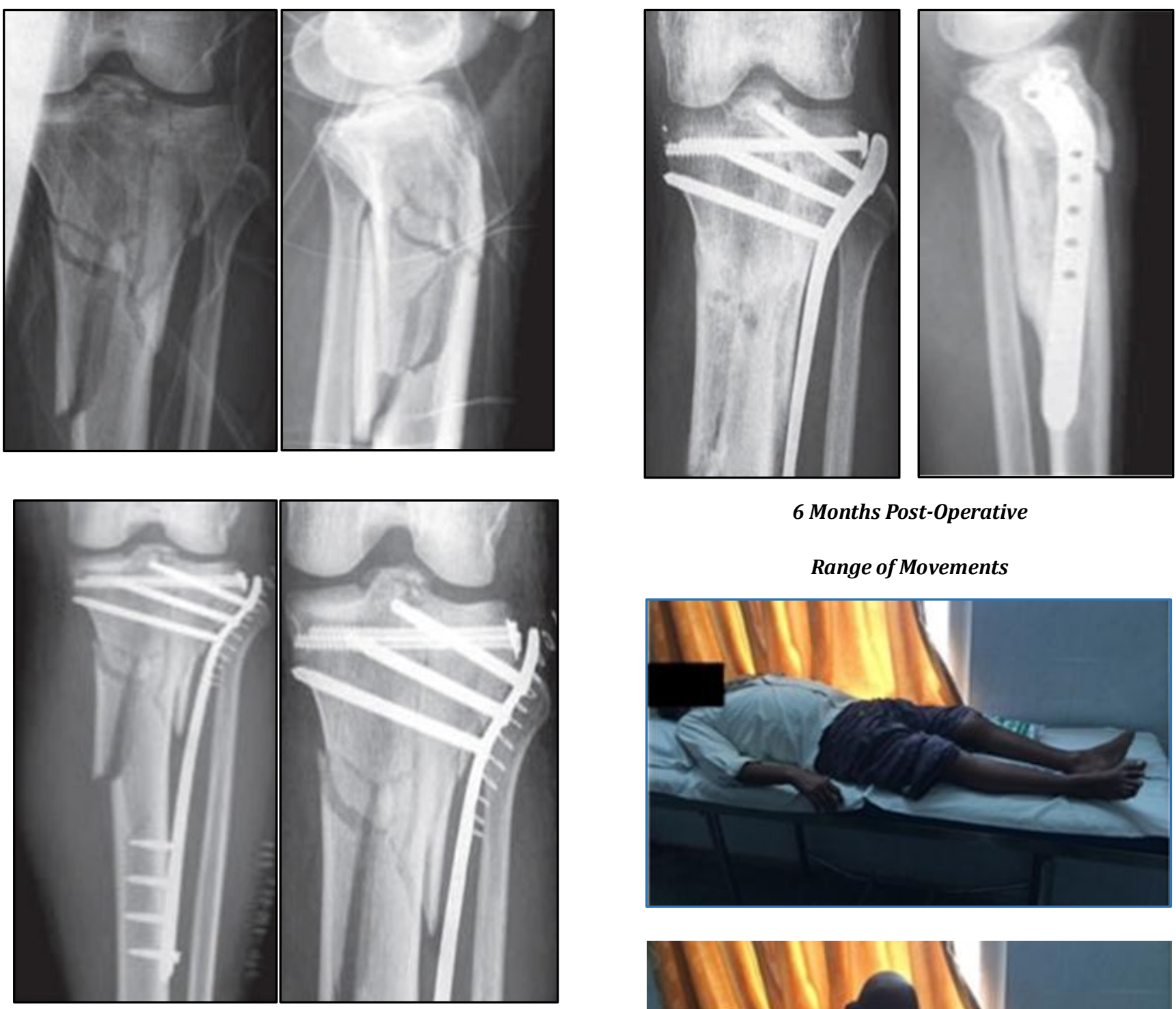

6 Months Post-Operative

Range of Movements

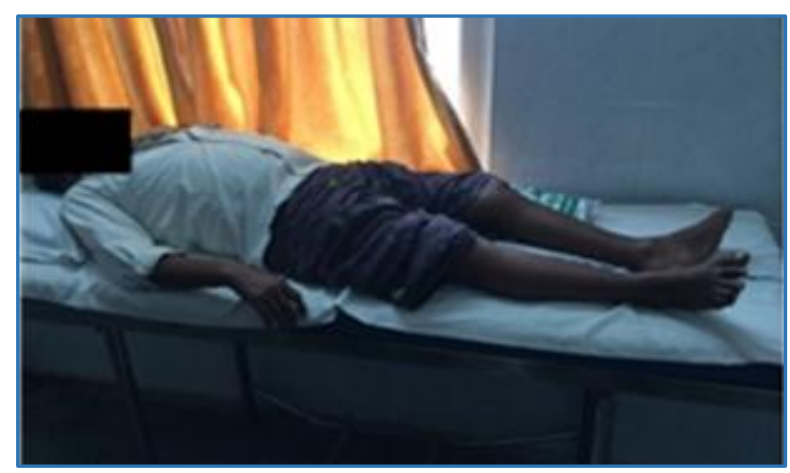

3 Months Post-Operative

6 Months Post-Operative
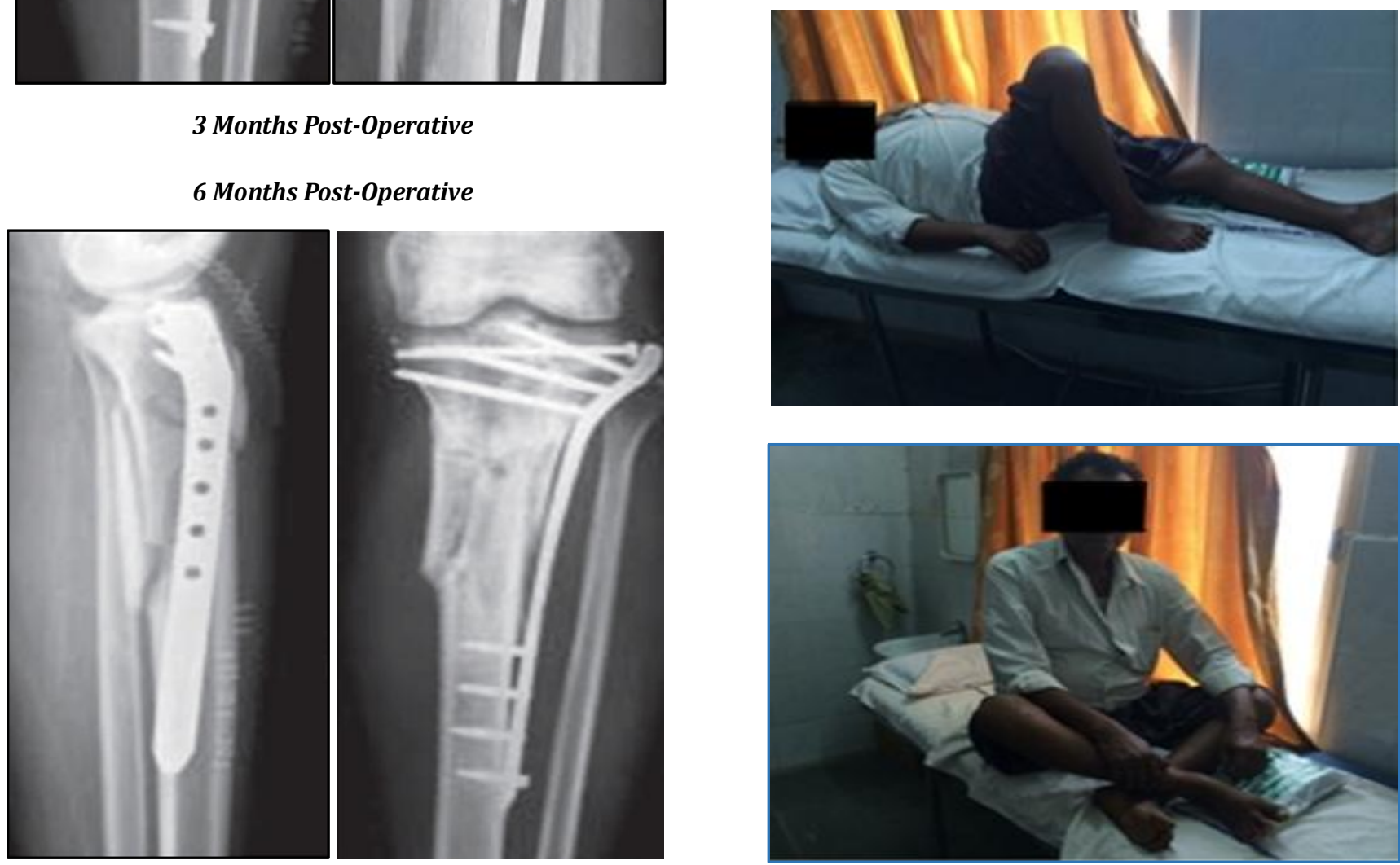

1 Year Post-Operative X-Rays 


\section{DISCUSSION}

The fracture of proximal tibia, which extend into the knee joint can produce major disability. At University of Iowa, authors began treating tibial plateau fractures with early application of a cost brace. They encouraged early motion, weight bearing to tolerance and unrestricted activities using crutches or other supports only when necessary lead to improved knee function.7

Percutaneous fixation offers its best in isolated undisplaced fractures, split unicondylar fractures and in elderly osteoporotic bone. The advantages are decreased operative time, less blood loss, smaller incision, short hospital stay and early rehabilitation. 8

In the early half of the 20th century, an author reported two studies having satisfactory percentage of good-toexcellent short- and long-term results with surgical method of treatment. ${ }^{9}$

In another published study of 159 cases of tibial plateau fracture of all types, treated by conservative (46\%) and surgery (54\%), evaluated by How and Luck method reported good-to-excellent result in surgery (84\%) than conservative method $(62 \%){ }^{10}$

Roberts in 1968 reported 100 cases of tibial condyle fractures treated by conservative and surgical. The result were good in $72 \%$ conservative, $80 \%$ traction mobilisation and $81 \%$ surgical. He advocated early mobilisation preservation for menisci and repair of torn ligaments for best results. ${ }^{11}$

Schatzker in 1979 reported 70 cases of tibial plateau fracture of all types treated by conservative (56\%) and surgical (44\%) with average followup of 28 months. Acceptable results were obtained in $58 \%$ of cases of conservative group and $78 \%$ by open methods. Fracture treated by ORIF with buttress plate and bone grafting achieved $88 \%$ acceptable results.

A study of 278 cases of tibial plateau fracture with an average followup of 2.5 years, all treated by surgical methods; $89 \%$ acceptable result when surgery was done by inexperienced surgeons, $97 \%$ when done by experienced. They concluded the prognosis improve with the experience and with accurate reconstruction of articular surface.

They also said post-traumatic osteoarthritis was directly proportional to the amount of displacement. 12

Gonzalez HY et al studied 122 injuries in 113 patients treated with the LCP and LISS. They found that despite the large number of open and comminuted fractures, no serious complications such as deep infections, non-unions, vascular lesions or deep venous thrombosis were noted. Also then concluded that the proven value of these systems (LCP and LISS) in complex fracture situations and revision surgeries. They found the procedure to be safe and reliable.13

Ring et al treated 24 patients with osteoporotic delayed union ( 9 patients) and non-union (15 patients) of the humeral diaphysis with the locking compression plate.

All the fractures eventually healed and using a modification of the Constant and Murley shoulder score the result were good or excellent in 22 patients and fair in 2 patients. They found that the construct provides stable fixation in patients with poor bone quality. ${ }^{14}$

Bjorkenheim JM et al retrospectively reviewed the complications and outcome after a period of 1 year in 72 patients with proximal humeral fracture, who were treated with proximal humeral locking plate. They encountered only 2 implant related complications of implant failure, which were due to a technical error. They concluded that the new proximal humeral locking plate is safe and can be recommended for the treatment of complex fracture of proximal humerus complicated by poor bone quality.

Thomas F et al in 2007 did a study on shimming a locking plates with washer to correct axial alignment. The author has used this in three cases of highly comminuted proximal tibial injuries; all fractures have healed uneventfully and all patients had full range of movement at 6 - 8 months measuring average 125-degree and side-to-side alignment by 2 - 4 degrees. ${ }^{15}$

\section{CONCLUSION}

We studied 21 patients with proximal tibial fracture with locking compression plate at N.R.I. Medical College and General Hospital, Chinnakakani, Guntur from September 2013 to October 2015.

- Age of the patients ranged from 18 - 65 yrs. with most of the patients belonging to 31 - 50 yrs. of age group, who are more prone for RTA.

- The majority of the patients were male ( $\mathrm{M}: \mathrm{F}=17: 4)$

- The sample size reflected the population visiting the trauma section of our department.

- Majority of the fractures were found to be type IV, type V, type VI and Schatzker's classification which are usually associated with high velocity RTA.

- Both ORIF and MIPO was used as the method of reduction and fixation, 5 patients were treated with MIPO technique.

- All patients were followed up ranged from 16 weeks to 64 weeks until fracture union occur.

- Average time for union of fracture was 18 weeks, ranged from (16 - 24 weeks); those plate bridge with the MIPO technique healed even earlier.

- Three different principle of fixation were done using the LCP, viz. compression, bridging and combined.

- We found that the locking screw had excellent hold even in the osteoporotic bones.

- We also suggest that the proper understanding principles of LCP and MIPO technique with preoperative planning of surgery can give good biological fixation for proximal tibial fractures.

\section{REFERENCES}

1. Koval KJ, Hulfet DL. Tibial plateau fractures: evaluation and treatment. J Am Acad Orthop Surg 1995;3(2):86-94.

2. Biyani A, Reddy NS, Chaudhary J, et al. The results of surgical management of displaced tibial plateau fractures in the elderly. Injury 1995;26(5):291-7.

3. Wagner M. General principles for the clinical use of the LCP. Injury 2003;34(Suppl 2):B31-42.

4. Sommer C, Gautier E, Muller M, et al. First clinical results of the Locking Compression Plate (LCP). Injury 2003;34(Suppl 2):B43-54.

5. Stoffel K, Dieter U, Stachowiak G, et al. Biomechanical testing of the LCP-how can stability in locked internal fixator be controlled? Injury 2003;34(Suppl 2):B11-9.

6. DeCoster TA, Nepola JV, el-Khoury GY. Cast brace treatment of proximal tibia fractures. A ten year follow up study. Clin Orthop Relat Res 1988;231:196-204.

7. Brown GA, Sprague BL. Cast brace treatment of plateau and bicondylar fracture of the proximal tibia. Clin Orthop Relat Res 1976;119:184-93. 
8. Sirkin MS, Bono CM, Reilly MC, et al. Percutaneous methods of tibial plateau fixation. Clin Orthop Relat Res 2000;375:60-8.

9. Palmer I. Compression fractures of the lateral tibial condyle and their treatment. J Bone \& Joint Surg 1939;2(3):674-80.

10. Duparc, Ficat. Fracture of the tibial plateau. In: Insall. Surgery of the knee. $2^{\text {nd }}$ edn. Vol 2. New York: Churchill Livingstone 1994. p. 1074.

11. Roberts JM. Fractures of the condyles of tibia, an anatomical and clinical end result study of 100 cases. J Bone \& Joint Surg 1968;50(8):1505-21.
12. Burri C, Bartzke G, Coldewey J, et al. Fractures of the tibial plateau. Clin Orthop Relat Res 1979;138:84-93.

13. Gonzalez HY, Mortin DA, Sanchez JF, et al. Early results with the new internal fixator systems LCP and LISS: a prospective study. Acta Orthop Belg 2007;73(1):60-9.

14. Ring D, Kloen P, Kadizielski J, et al. Locking compression plates for the osteoporotic nonunions of the diaphyseal humerus. Clin Orthop Relat Res 2004;425:50-4.

15. Higgins TF. "Shimming" a locking plates with washers to correct axial alignment. J Orthop Trauma 2007;21(6): 400-3. 